\title{
Espécie nova de Parasetomima Duckhouse (Diptera, Psychodidae) do nordeste brasileiro
}

\author{
Freddy Bravo \\ Departamento de Ciências Biológicas, Universidade Estadual de Feira de Santana. Avenida Universitária, 44031-460 Feira de \\ Santana, Bahia, Brasil. E-mail: fbravo@uefs.br
}

\begin{abstract}
A new species of Parasetomima Duckhouse (Diptera, Psychodidae) from northeastern Brazil. A new species of Psychodidae, Parasetomima ornata from Bahia, northeastern Brazil, is described. It is the second species of the genus Parasetomima Duckhouse, 1968 described.
\end{abstract}

KEY WORDS. Parasetomima ornata, new species, neotropics, Brazil.

RESUMO. Neste trabalho descreve-se Parasetomima ornata, uma nova espécie de Psychodidae da Bahia, nordeste do Brasil. Esta é a segunda espécie descrita para o gênero Parasetomima Duckhouse, 1968.

PALAVRAS CHAVE. Parasetomima ornata, região neotropical, Brasil.

O gênero Parasetomima Duckhouse, 1968 foi proposto para $P$. umbella Duckhouse, 1968. A espécie tipo deste gênero foi descrita a partir de dois machos coletados em Nova Teutônia (Seara), Santa Catarina, sul do Brasil em 1937 por Fritz Plaumann (DuckHouse 1968). Uma espécie nova de Parasetomima do nordeste brasileiro é descrita neste trabalho.

Os espécimes foram coletados com armadilha luminosa tipo “Luiz de Queiroz" na Serra da Jibóia (1251’S - 39³0`W), Município de Santa Terezinha, Bahia, distante aproximadamente $100 \mathrm{Km}$ da costa leste e inserida no Bioma Mata Atlântica.

Todos os exemplares estudados foram tratados com solução aquosa de hidróxido de potássio $(\mathrm{KOH})$, montados em lâmina permanente e posteriormente depositados na Coleção Entomológica da Universidade Estadual de Feira de Santana (CUFS), Feira de Santana, Bahia. Segue-se a terminologia de Duckhouse (1987) para a terminália masculina.

\section{Parasetomima ornata sp. nov.}

Figs $1-5$

Material-tipo. Holótipo macho, Brasil, Bahia: Santa Terezinha (Serra da Jibóia), 17.VI.2003, I. Castro leg. (CUFS). Três parátipos macho, mesma localidae do holótipo: 24.VIII.2000, F. Bravo leg. (CUFS); 27.IX.2000, F. Bravo leg. (CUFS); 19.X.2000, I. Castro leg. (CUFS).

Etimologia. O nome da espécie é alusivo ao prolongamento anterior do cerco.

Holótipo macho. Comprimento do corpo, desde o início do tórax até o final do abdome 2,4 $\mathrm{mm}$. Cabeça subcircular, ponte ocular de três facetas de largura, separadas por distância pouco menor ao diâmetro da faceta. Antena incompleta, escapo subcilíndrico (Fig. 1); pedicelo subesférico (Fig. 1); flagelômeros fusiformes; flagelômeros apicais do mesmo comprimento que os basais (Fig. 1); ascóides digitiformes, 1,5 o comprimento de um flagelômero (Fig. 1). Palpo maxilar com quatro segmentos (Fig. 2); comprimento relativo dos palpômeros: $1,0: 2,0: 2,4: 2,8$. Asa: membrana alar preto hialina com manchas claras na superfície alar (Fig. 3); comprimento da asa 2,6 $\mathrm{mm}$; largura máxima $1,1 \mathrm{~mm}$; $\mathrm{R}_{5}$ terminando no ápice; $\mathrm{Rs}$ pectinada (Fig. 4). Tergito 9, cercos, gonocoxito e gonóstilo com pilosidade (Figs 4, 5). Gonocoxito quase do mesmo comprimento que o gonóstilo, subtriangular em vista lateral (Fig. 5); gonocoxito esquerdo com prolongamento apical espiniforme; gonocoxito direito sem esse prolongamento. Par de processos digitiformes na base dos gonocoxitos, as gonapófises de DuckHouse (1968); esquerdo maior que o direito. Gonóstilo pouco esclerotinizado, digitiforme, com o ápice curvado (Figs 4, 5). Esternito 9 estreito, unindo os gonocoxitos (Fig. 4). Esclerito estreito unindo os gonocoxitos, separado do esternito 9, provavelmente corresponde à placa pós-hipandrial dos outros psicodíneos (Fig. 4). Esternito 10 com micropilosidade apical na superfície dorsal (Fig. 4). Tergito 9 subquadrado. Cerco largo na base, estreito no ápice, com projeção posterior comprida e estreita, terminando em cerda umbelada (Figs 4, 5); tenácula digitiforme (Figs 4, 5). Edeago assimétrico, ápice pontiagudo (Fig. 4). Apôdema edeagal curto, duas vezes o comprimento da placa pós-hipandrial (Fig. 4). Apôdema gonocoxal quase do mesmo comprimento do apôdema edeagal (Fig. 5).

Comentários. Em Parasetomima ornata sp. nov. observouse polimorfismo na terminália masculina. A descrição do gonocoxito e das apófises realizada para o holótipo é observada em um dos parátipos. Dois outros parátipos apresentam a condição inversa a observada no holótipo para o formato do gonocoxito e disposição das gonapófises, ou seja, o gonocoxito direito possui o prolongamento apical espiniforme, enquanto

Revista Brasileira de Zoologia 21 (2): 281-282, junho 2004 


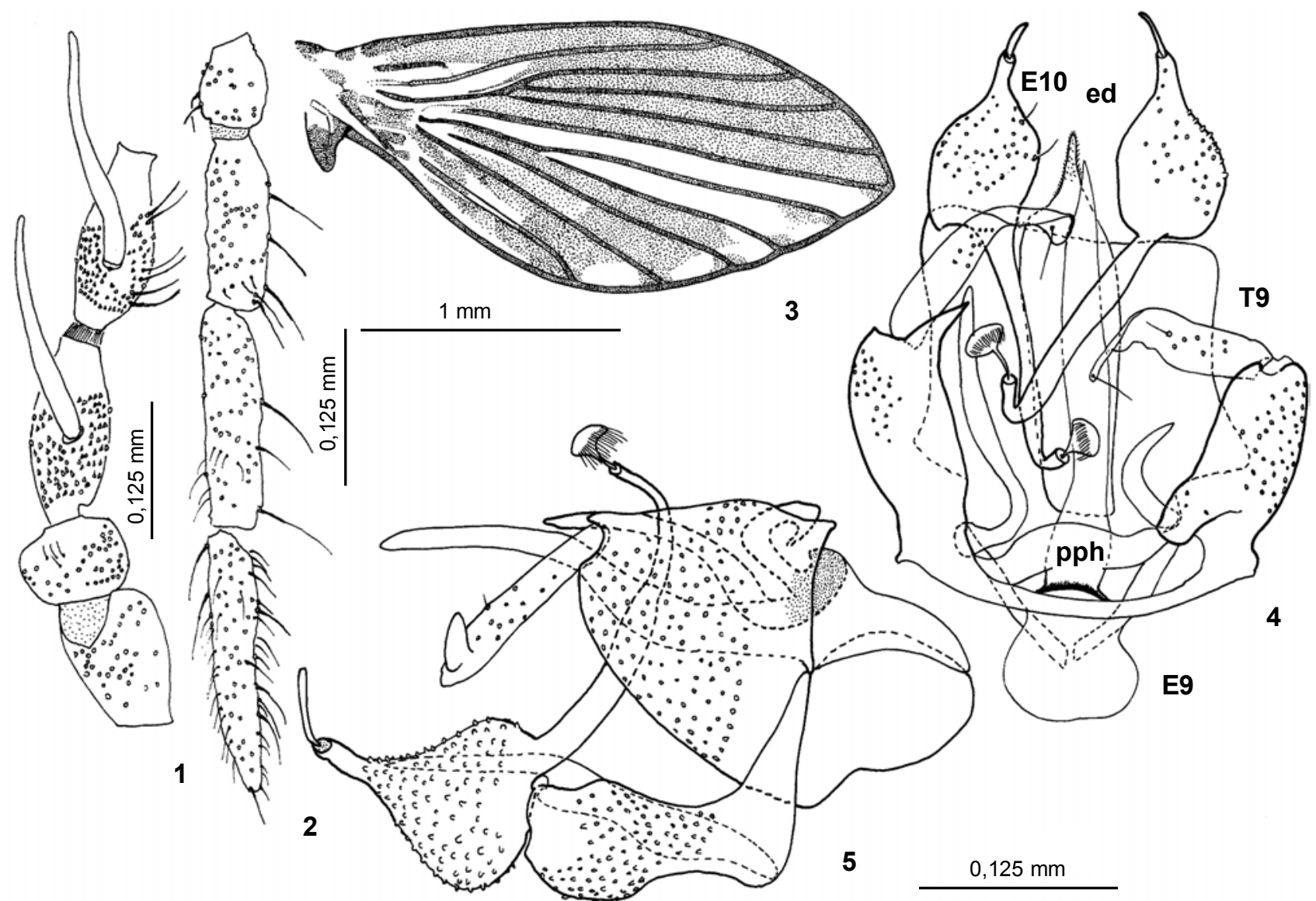

Figuras 1-5. Parasetomima ornata sp. nov.: (1) escapo, pedicelo e dois primeiros flagelômeros; (2) palpo maxilar; (3) asa direita; (4) terminália masculina, vista dorsal; (5) terminália masculina, vista lateral. (ed) Edeago, (E9) esternito 9, (E10) esternito 10, (pph) placa pós-hipandrial, (T9) tergito 9.

que o direito não tem esse prolongamento e a gonapófise direita é maior que a esquerda.

Parasetomima ornata sp. nov. diferencia-se de P. umbella pelo tamanho do apódema edeagal e pelo formato das gonapófises. O apódema gonocoxal de P. ornata sp. nov. é a metade do comprimento dos gonocoxitos, enquanto que em $P$. umbella o apódema edeagal é do mesmo tamanho. As gonapófises em $P$. umbella são retas e não curvas como em $P$. ornata sp. nov., sendo a direita pouco maior que a esquerda. As gonapófises de $P$. ornata sp. nov. são bem maiores que as de $P$. umbella, sendo que a maior chega ao dobro da menor, enquanto que as de $P$. umbella são quase do mesmo comprimento.

Outra diferença observada entre as duas espécies é quan- to a presença de manchas claras na membrana alar de $P$. ornata sp. nov., manchas que $P$. umbella não possui.

\section{REFERÊNCIAS BIBLIOGRÁFICAS}

Duckhouse, D.A.1968. Psychodidae (Diptera, Nematocera) collected by Mr. Palumann in southern Brazil. Procedings of the Royal Entomological Society of London (B) 37: 29-40.

. 1987. A revision of Afrotropical Setomima, elucidation of their genealogical relationships and description of other Psychodinae (Diptera: Psychodidae). Annals of the Natal Museum, Pietermaritzburg, 28: 231-282.

Recebido em 11.XI.2003; aceito em 27.V.2004.

Revista Brasileira de Zoologia 21 (2): 281-282, junho 2004 